\title{
Nota sobre la identidad del tepescohuite en México
}

Recientemente ha surgido un gran interés por la planta popularmente conocida como tepescohuite, denominada también "árbol de piel", por las propiedades medicinales que se le atribuyen para la curación de heridas y quemaduras. Por lo anterior, consideramos importante presentar esta nota sobre su identidad taxonómica, incluyendo las características distintivas de la planta y algunos comentarios sobre su distribución geográfica.

Diversos ejemplares recibidos para identificación bajo el nombre común de tepescohuite y provenientes de Oaxaca y Chiapas, así como las propias colectas de la autora en dichos estados, han sido determinados como Mimosa tenuiflora (Willdenow) Poiret.

La historia nomenclatural de esta planta es interesante; fue descrita por primera vez en el año de 1806, por Willdenow, como Acacia tenuiflora de Venezuela. Posteriormente, Poiret hizo la transferencia de esta especie al género Mimosa en 1810.

Por otra parte, Karsten describió Mimosa cabrera, de Colombia, en el año de 1863. Bentham (1875) considera que Mimosa cabrera y M. tenuifora (Willd.) Poiret son sinónimos; Robinson (1898) no coincide con Bentham y señala esta sinonimia como dudosa.

Huber, por su parte, describió Mimosa nigra del Brasil en 1901.

Con base en la revisión de descripciones originales, de ejemplares de los herbarios GH, MEXU, MO, NY, UAMIZ, US (que cubren toda el área de distribución de esta planta) y después de diversas observaciones de campo realizadas en México, se concuerda con la opinión de Bentham (1875) y se considera que M. tenuiflora (Willd.) Poiret y M. cabrera Karsten son sinónimos; se concluye que Mimosa nigra Huber es un nuevo sinónimo para este taxón, cuyo nombre correcto y sinonimia se presentan a continuación:

Mimosa tenuiflora (Willdenow) Poiret. In: Lamarck, Encycl. Méth. Bot. Suppl. 1:82. 1810, non Mimosa tenuiflora Bentham, London J. Bot. 5:92. 1846.

Acacia tenuiflora Willdenow, Sp. Pl. 4:1088, 1806. TIPO: VENEZUELA, Caracas, Bredemeyer 20 (B-Willd., Microficha IDC 7440. 1391:I. 9.

Mimosa cabrera Karsten, Fl. Columb. 2:63, t. 132. 1863. TIPO: COLUMBIA (Colombia): planicies septentrionales, cálidas y secas (tabla 132!)

Mimosa nigra Huber, Bull, Herb. Boissier, ser. 2, 1:303, 1901. TIPO: BRASIL, Ceará, Sertâo, prés Quixadâ, Huber 309 (Museo Paraense).

Mimosa tenuiflora Bentham es un homónimo posterior de M. tenuiflora (Willd.) Poiret, por lo que fue rechazado y se propuso un nuevo nombre para esa planta: Mimosa zimapanensis (Britton. In: Britton y Rose, N. Amer. Fl. 23:166. 1928). Esta especie, conocida de la región de Zimapán en el estado de Hidalgo, es completamente diferente de $M$. tenuiflora (Willd.) Poiret, ya que entre otras diferencias presenta flores dispuestas en cabezuelas y fruto con valvas enteras.

Grether R. 1988. Nota sobre la identidad del tepexcohuite en México. Boletín de la Sociedad Botánica de México 48: 151-152. 
Mimosa tenuiflora (Willd.) Poiret se caracteriza por presentar hojas con 5-10 pares de pinnas y 10-30 pares de foliolos lineares, de 3-6 mm de largo y $0.7-2 \mathrm{~mm}$ de ancho; flores blancas agrupadas en espigas densas, de 3-6.5 cm de largo y fruto lanceolado, inerme, comprimido entre las semillas, de $2-4.5 \mathrm{~cm}$ de largo y 5-7 $\mathrm{mm}$ de ancho, con 2-6 artejos. Las ramas jóvenes, las hojas y los frutos inmaduros presentan pelos glandulares y/o glándulas.

Por otra parte, esta especie ha sido confundida en diversas ocasiones con Mimosa arenosa (Willd.) Poiret, ya que ambas son parecidas y su área de distribución se sobrelapa en algunas partes. M. arenosa difiere de $M$. tenuiflora por sus flores pediceladas, agrupadas en espigas laxas no mayores de $4 \mathrm{~cm}$ de largo, con el fruto linear-oblongo, no comprimido entre las semillas, con 5-11 artejos y por la ausencia de pelos glandulares y glándulas en las ramas jóvenes y hojas, aunque los frutos ocasionalmente presentan puntos resinosos escasos.

Mimosa tenuiflora (Willd.) Poiret tiene una amplia distribución en América (Grether, 1984); a la fecha, se conoce de Brasil, Venezuela, Colombia, Panamá, El Salvador, Honduras y México.

Esta especie ha sido citada para México por diversos autores (Standley, 1922; Britton y Rose, 1928; Miranda, 1976; Breedlove, 1986).

Su área de distribución en México comprende los estados de Oaxaca y Chiapas. En Oaxaca se le ha encontrado principalmente en la región del Istmo de Tehuantepec y en Chiapas tiene una amplia distribución en la porción central y suroeste del estado. Es uno de los elementos importantes de las selvas bajas caducifolias, aunque con frecuencia forma matorrales casi puros y la hemos observado, en forma más escasa, en bosques de pino-encino.

Esta especie, como muchas otras del género Mimosa, es favorecida por la perturbación, de manera que con frecuencia se le encuentra a la orilla de los caminos y veredas, así como en áreas taladas y/o quemadas.

Durante mucho tiempo esta planta ha sido considerada como una maleza difícil de eliminar, que invade milpas y cultivos abandonados (Miranda, 1976); dado el reciente interés por su uso medicinal y la elaboración de diversos productos a partir de esta planta a nivel local, en algunas partes de Oaxaca y Chiapas la gente del lugar empieza a cuidarla como un recurso; sin embargo, en otras especies se observa ya una explotación intensa de esta especie.

\section{LITERATURA CITADA}

Bentham, G., 1875. Mimosa. In: Revision of the Suborder Mimoseae. Trans. Linn. Soc. London 30:416. Breedlove, D.E., 1986. Listados floristicos de México IV. Flora de Chiapas. Instituto de Biología, UnAm, México. pp. 105.

Britton, N.L. y J.N., Rose, 1928. Mimosa. North Amer. Fl. 23:144-171.

Grether, R., 1984. Notes on the genus Mimosa in Mesoamerica. Bull. Int. Group. Study Mimosoideae 12:43-48. Miranda, F., 1976. La vegetación de Chiapas, Segunda Parte. Tuxtla Gutiérrez, Chis. 2a. ed. pp. 206-278. Robinson, B.L., 1898. Revision of the North American and Mexican species of Mimosa. Proc. Amer. Acad. Sci. 23:321.

Standley, P.C., 1922. Mimosa. In: Trees and Shrubs of Mexico. Contr. U S Natl. Herb. 33(1):360.

Rosaura Grether. Departamento de Biología. División C.B.S. Universidad Autónoma MetropolitanaIztapalapa. Apdo. Postal 55-535, 09340 México D.F. 